\title{
AN ANALYTICAL, STATISTICAL STUDY OF THYROID CANCER INCIDENCE IN SUDAN DURING 2005-2015
}

\author{
Abdelkareem A. Ahmed ${ }^{1,5,7^{*}}$, Hassan H. Musa ${ }^{2,7}$, Taha H. Musa ${ }^{3,7}$, Idriss H. Musa ${ }^{4}$, Amal Z. \\ Sifaldein ${ }^{1}$, Mohammed Elmujtba Adam Essa ${ }^{5}$, Alfatih Ismael Adam ${ }^{6}$
}

\author{
${ }^{1}$ Department of Physiology and Biochemistry, Faculty of Veterinary Science, University of \\ Nyala,Nyala, Sudan \\ ${ }^{2}$ Department of Medical Microbiology, Faculty of Medical Laboratory Science, University of Khartoum, \\ Khartoum, Sudan \\ ${ }^{3}$ Key Laboratory of Environmental Medicine Engineering, Ministry of Education. Department \\ Epidemiology and Health Statistics, School of Public Health, Southeast University, Nanjing, 210009, \\ Jiangsu Province, China \\ ${ }^{3}$ Biomedical Research Institute, Darfur University College, Nyala, Sudan \\ ${ }^{4}$ Sudan Medical Specialization Boards, Sudan \\ ${ }^{5}$ Department of Cancer Research and Awareness, Medical and Cancer Research Institute, Nyala, \\ Sudan. \\ ${ }^{6}$ Department of Internal Medicine, zalingei teaching hospital, zalingei, Sudan. \\ ${ }^{7}$ Darfur University College, Nyala, Sudan.
}

${ }^{*}$ Corresponding author: kareemo151@gmail.com 


\begin{abstract}
Introduction: Sudan, the most diverse country in the African continent, is experiencing growing cancers problems. However, little is known about thyroid cancer epidemiology and patterns. the study aimed to analyse and describe the epidemiological characteristics and trends of thyroid cancer in, in the period $1^{\text {st }}$ January 2005 and $31^{\text {st }}$ December 2015. Methods: This is retrospective population and hospital-based study. We analysed epidemiological data for digital medical records at both Radiation and Isotope Centre Khartoum (RICK), and Soba University Hospital, Khartoum, Sudan were reviewed. Results: In total, 1,062 cases were reported during 1st January 2005 and $31^{\text {st }}$ December 2015. Of these, (360; $33.9 \%)$ were male and $(702 ; 66.1 \%)$ were female. The highest number of cases was in the $25-54$-yearold age group $(451 ; 42.5 \%)$, and more than 65 -year-old age $(331 ; 31.2 \%)$. The most predominant type of thyroid cancer among the Sudanese population was Papillary carcinoma $(734 ; 69.1 \%)$ followed by Follicular carcinoma 178(16.8\%) and Medullary carcinoma (150; 14.1\%). There were significant differences in gender, age groups and types of thyroid cancer $(P=0.001)$. Based on geographical distribution thyroid cancer showed high prevalence in Khartoum, North Kurdufan, River Nile, Kassala, North Darfur, Northern, and south Kurdufan. Whereas, low distribution is seen in Red sea, West Darfur, West Kurdufan, East Darfur, Al Gadarif, and the Blue Nile. Conclusion: our results suggest that thyroid cancer continuous presenting alarming challenge with an increasing the prevalence in females. Papillary carcinoma is the most common type among Sudanese populations. Further epidemiological studies are required in policy strategies for control and prevention strategies of thyroid cancer in Sudan.
\end{abstract}

Keywords: Epidemiology, Sudan, Thyroid Cancer 


\section{Introduction}

Thyroid cancer comprises approximately two percent of all cancers types diagnosed global and $95 \%$ of all endocrine cancers (Sipos \& Mazzaferri, 2010). Recent studies indicate a continuous increase in thyroid tumours occurrence worldwide. In some geographical regions, this increase exceeds $100 \%$ (Kilfoy et al., 2009). However, small decreases in the incidence of thyroid cancer were reported in a few regions (Kilfoy et al., 2009). It has been proposed that this generally steady trend of increasing thyroid cancer incidence present in all continents except Africa, where the diagnosis detection is possibly inadequate (Pellegriti et al.,2013). Several factors such as genetic factors, environmental factor (llias et al.,2002), nutritional status (Dal Maso et al.,2009), and availability of medical care (Yabroff et al.,2019) might contribute in the thyroid cancer incidence by ethnicity and geographic area. Based on recent reports, thyroid cancer is the fifth most frequent cancer in female (Siegel et al., 2014) and it is the second most common cancer in women below 45 years old in Italy (Dal Maso et al., 2011). A few countries such as Norway and Sweden are capable to decrease the incidence of thyroid

Recent reports indicate that the treatment and follow-up costs of thyroid cancer can be reduced in low-risk tumours by selective,
cancer(Kilfoy et al., 2009). However, relevant information in Sudan is missing.

Despite of the gradually increased incidence, thyroid cancer mortality rate is reported constant at approximately 0.5 cases per 100,000 patients (Liu et al., 2017; Olson et al.,2019). Compared with other types (including colon-rectum, breast, prostate cancer, and lung) whose mortality rate has decreased in the last two decades, thyroid cancer mortality rate is slightly increased (Pellegriti, et al., 2013).Explanations for the thyroid cancer incidence increase worldwide are controversial (Ito et al., 2013). Some scientists believe that the increase is due to the increased diagnostic tools (Davies \& Welch, 2006; Grodski et al., 2009), whereas other scientists believe that the real increase is due to lifestyle (Mack et al., 2002) and environment changes(Fiore et al., 2019; Nettore et al., 2018). The problem is of socioeconomic (Zevallos et al., 2014) and medical relevance(Lin et al., 2017). The financial cost of thyroid cancer over diagnosis patient can vary from hundreds to thousands of dollars, based on the extent of the laboratory examinations been done and the complexity of the intervention and follow up (Boltz et al., 2013; Schlumberger et al., 2011)

simplified procedures (Ahmed \& Essa, 2019; Alexander \& Larsen, 2012; Schlumberger et al., 2012).

Currently, this is the most suitable approach, depending on the judgment of different prognostic factors which affect the patient outcome.

Sudan does not have a cancer registry-based on national population. The most important 
sources of cancer statistics are the hospitalbased case series. There are only two centres in the country, both located in central Sudan, the area with a high density of population. For instance the Radiation and Isotope Centre in Khartoum (RICK), Khartoum State (Figure 1), and the National Cancer Institute of the University of Gezira (NCl-UG) in Wad Medani, Gezira State (Previously "Institute of Nuclear Medicine Molecular Biology \& Oncology", INMO). Additionally, in the 1960s to 1980s, there was the Sudan Cancer Registry (SCR), which was mainly based on histopathological diagnosed confirmation. It was under the National Health Laboratories authority. Currently, RICK is the main source for the cancer registry in Sudan. The description of epidemiological characteristics and trends of thyroid cancer in Sudan has not been reported. Moreover, it remains unknown whether women are affected earlier than men and, therefore, suffer greater professional, economic, and social impacts. Consequently, the study aimed to analyse and describe the epidemiological characteristics and trends of thyroid cancer in, in the period $1^{\text {st }}$ January 2005 and $31^{\text {st }}$ December 2015.

\section{Methods}

There were two main types of cancer registry in Sudan: hospital-based and population-based cancer registries. Estimated cancer cases were unknown in Sudan because of the absence of the population-base cancer registry. The first cancer registry was practical from the early sixties (1960s) to the early eighties (1980s). It was based on histopathologically confirmed cases diagnosed mostly at the National Health Laboratories of public health in Khartoum (Stack). Today, Radiation and Isotope Centre Khartoum (RICK) is the main source of hospitalbased cancer registry in Sudan. This is a retrospective study conducted by using the digital records at both RICK and Soba University Hospital from 2005-2015. These registries were created by the ministry of federal health for the diagnosis, treatment and epidemiological surveillance of all cancer types in Sudan. The data used in this study contains 1,062 thyroid cancer patients, including the sex of the patients, age, geographical region and type of thyroid cancer were reported. Each thyroid cancer diagnosis start from the outpatient clinic where relevant history and clinical examination have been done, in addition to lab and imaging investigation which include, Complete Blood count (CBC), Thyroid function test (TFT), Renal Profile, Calcium Blood level, Liver function test, thyroid Ultra Sound, Computer Tomography (CT) for the thyroid gland and Fine needle aspiration (FNA) from thyroid gland tissues for histopathology, and the final confirmation of the diagnosis made by clinical oncologist but no gene test was available.

We found that almost every thyroid cancer patients from all regions of Sudan transferred to the RICK and Hospital for more confirmation and treatment. This database was the data source for the present population-based report. 


\section{Statistical analysis}

The collected data were stored using the computer program. Nominal data are expressed as frequency or proportion. All statistical analysis was performed using the Statistical Analysis Package for Social Science (SPSS, v.22.0 Chicago, Illinois, USA) with a level of the significant set at $(P<0.05)$.

\section{Results}

The frequency differences between males and females within different types of thyroid cancer were presented in Figure 2.

A total of 1062 cases were investigated by thyroid cancer in Sudan from1January 2005 to 31 December 2015. Of these, (360; 33.90\%) were males, and(702; 66.10\%) were females cases were diagnosed and confirmed by the types of thyroid cancer. Papillary carcinoma reports high frequency in Follicular carcinoma (178; 16.76\%), and Medullary carcinoma (150; $14.12 \%$ ) were reported. Where age $25-54$ years are more infected group by thyroid cancer (451; $42.47 \%$ ). The high prevalence of thyroid cancer was reported in the age group 25-54 years as $451(42.5 \%)$, and the lower incidencewas noticed in aged $15-24$ years as $(58 ; 5.5 \%)$.

Another fact that papillary carcinoma (734; $69.1 \%$ ) is a large type of thyroid cancer reported among Sudanese population. Females were showed high affected groups compared to male groups. The finding seen that thyroid cancer had most common in female than male patients. Within 10 years, the monitoring assessment of thyroid cancer cases showed that significant differences $(P=0.001)$ difference between male and female, age groups $(P=0.001)$, and between the different types of thyroid cancer $(P=0.001)$ as presented in Table 1.

The trend of thyroid cancer cases by sex, age group, and type of thyroid cancer during the tenyears were presented in Table 2.Khartoum, Gazira, North Kurdufan, River Nile,Kassala, and North Darfur were reported higher cases of thyroid cancer compared with other cities during the study period Figure 3.

\section{Discussion}

Thyroid cancer comprises approximately $2 \%$ of all cancers diagnosed worldwide and $95 \%$ of all endocrine cancers (Drabe et al., 2016; Nguyen et al., 2015). Recent reports indicate that there is a progressive increase in thyroid malignancy worldwide in 2013 (Pellegriti et al., 2013). In the present study, we observed an increasing trend in the incidence of thyroid cancer in Sudan. This trend seems to be similar to that of worldwide (Pellegriti et al., 2013). The increases of thyroid cancer could be attributed to the environmental factors such as pollution (Awadelkarim, et al., 2012), exposure to radiation (Miyakawa, 2014) as well as iodine deficiency. In the present study, we have reported for the first time the epidemiology of thyroid cancer in Sudan. Women are more affected by thyroid cancer than men. This may explain gender differences (Yao et al., 2011).

Table 1: Characteristic of the study population

\begin{tabular}{llll}
\hline Variables & No. & $(\%)$ & P-value \\
\hline Gender & & & \\
\hline
\end{tabular}




\begin{tabular}{llll}
\hline Male & 360 & 33.9 & 0.001 \\
$\quad$ Female & 702 & 66.1 & \\
$\quad$ Total & 1062 & & \\
$\begin{array}{l}\text { Age groups (years) } \\
\text { 15-24 }\end{array}$ & 58 & 5.5 & 0.001 \\
$25-54$ & 451 & 42.5 & \\
$55-64$ & 222 & 20.9 & \\
$<65$ & 331 & 31.2 & \\
Type of thyroid cancer & & & \\
$\quad$ Follicular & 178 & 16.8 & 0.001 \\
Papillary & 734 & 69.1 & \\
$\quad$ Medullary & 150 & 14.1 & \\
\hline
\end{tabular}

Table 2: The trendof thyroid cancer cases by gender, age group during the period 2005-2015.

\begin{tabular}{|c|c|c|c|c|c|c|c|c|c|c|c|}
\hline Variables & 2005 & 2006 & 2007 & 2008 & 2009 & 2010 & 2011 & 2012 & 2013 & 2014 & 2015 \\
\hline \multicolumn{12}{|l|}{ Gender } \\
\hline Males & 6 & 37 & 38 & 19 & 21 & 22 & 24 & 43 & 52 & 24 & 74 \\
\hline Females & 10 & 58 & 70 & 64 & 39 & 33 & 86 & 75 & 99 & 48 & 120 \\
\hline Total & 16 & 95 & 108 & 83 & 60 & 55 & 110 & 118 & 151 & 72 & 194 \\
\hline \multicolumn{12}{|l|}{ Age groups } \\
\hline $15-24$ & 0 & 6 & 9 & 5 & 3 & 5 & 8 & 6 & 9 & 1 & 6 \\
\hline $25-54$ & 6 & 43 & 41 & 41 & 27 & 24 & 53 & 52 & 59 & 26 & 79 \\
\hline $55-64$ & 4 & 15 & 18 & 19 & 18 & 11 & 21 & 27 & 31 & 19 & 39 \\
\hline$<65$ & 6 & 31 & 40 & 18 & 12 & 15 & 28 & 33 & 52 & 26 & 70 \\
\hline \multicolumn{12}{|c|}{ Type of thyroid cancer } \\
\hline Follicular & 3 & 17 & 14 & 12 & 11 & 6 & 12 & 18 & 15 & 5 & 65 \\
\hline Papillary & 10 & 64 & 77 & 62 & 44 & 45 & 90 & 91 & 122 & 64 & 65 \\
\hline Medullary & 3 & 14 & 17 & 9 & 5 & 4 & 8 & 9 & 14 & 3 & 64 \\
\hline
\end{tabular}

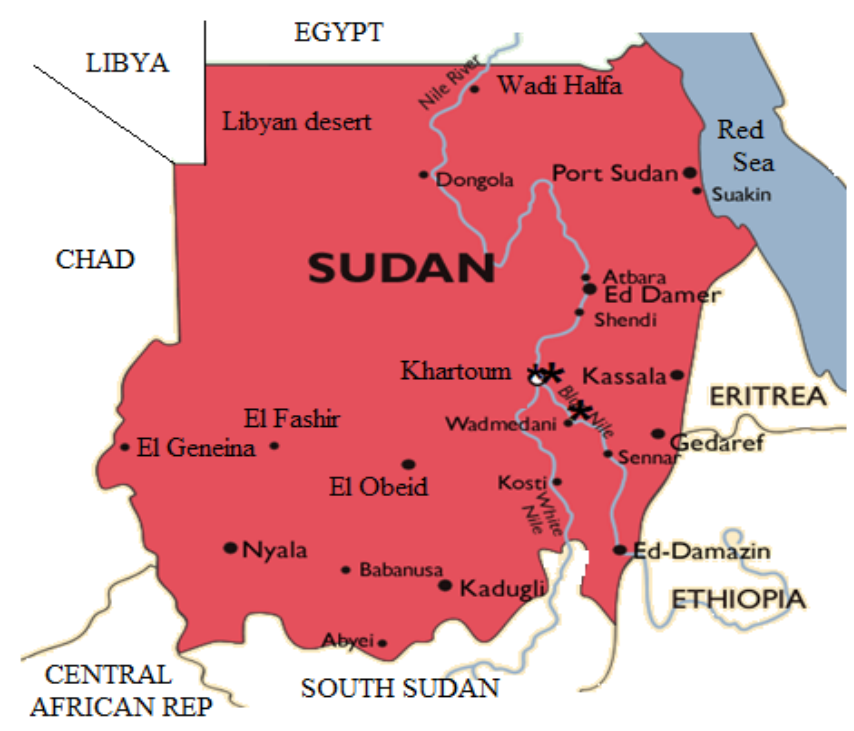


Figure 1: Map of Sudan after referendum (Retrieved from

https://images.app.goo.gl/4x1jk3Di7oW7kz38A)

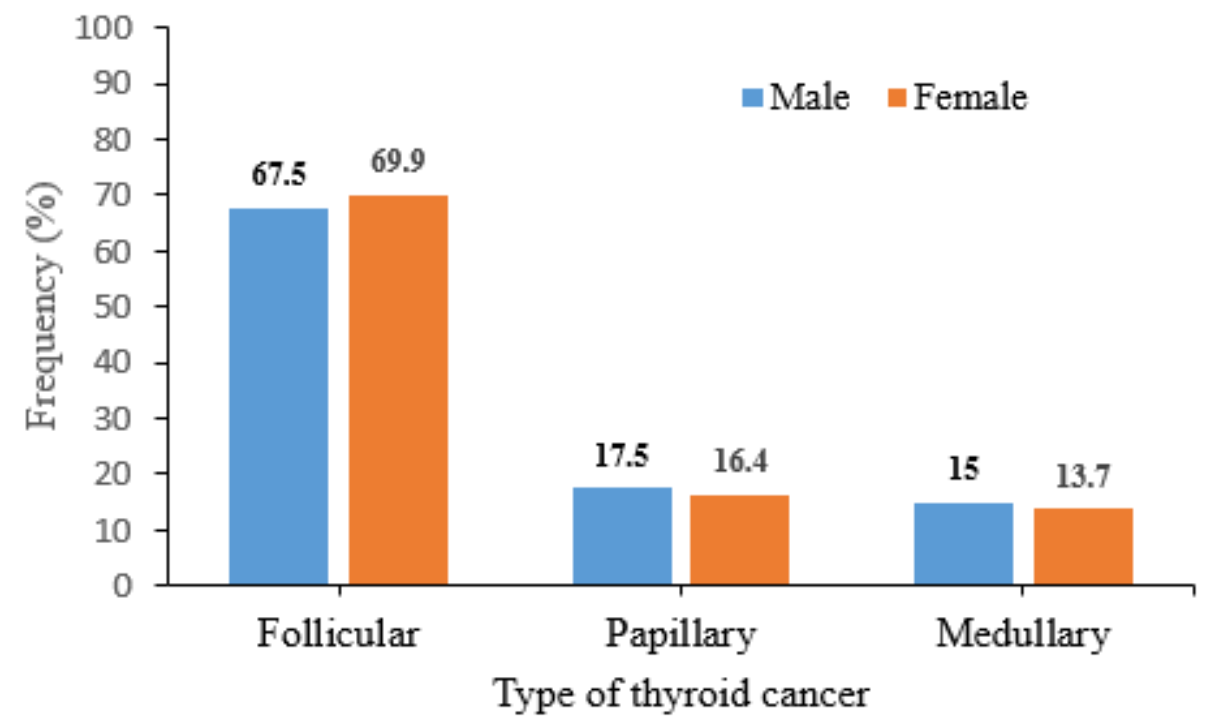

Figure 2: Frequency distribution of type of thyroid cancer by gender

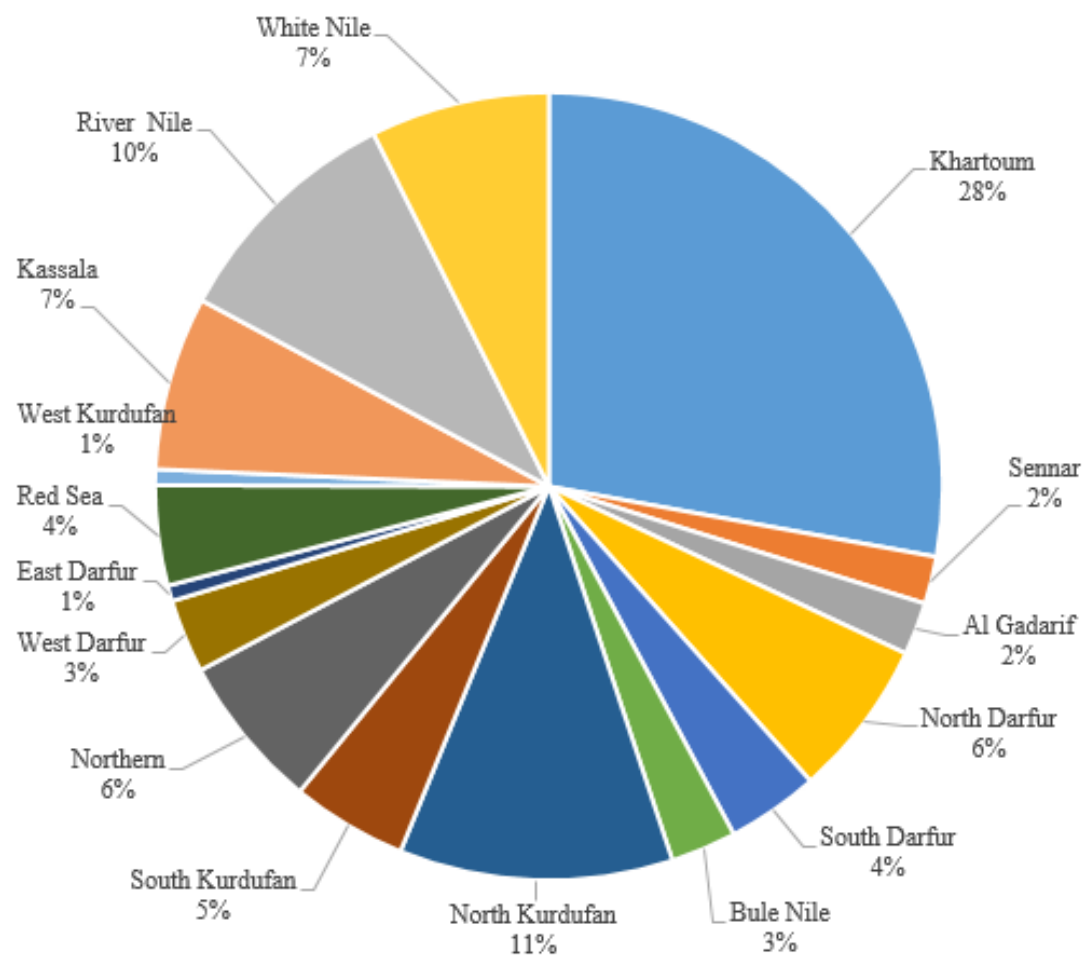

Figure 3: Frequency distribution rate of thyroid cancer by cities among Sudanese population 
hormonal factor (Horn-Ross, et al., 2011), dietary factor (Choi \& Kim, 2014) employment factor (Kuzmickiene \& Stukonis, 2010) or economic status (Kim et al., 2014). Thus, women are suffering greater professional, economic, and social impacts in Sudan. In the present study, ethnic cancer risk factors were seen in some Sudanese ethnic groups was more affected than others. Our findings are agreed with previous reports that the incidence of thyroid cancer associated with the ethnic group (Finlayson et al., 2014a). In the present study, the time trends analysis indicated a stable increase in the incidence of thyroid cancer in Sudan. This trend is widespread in many national and international geographical areas (Pellegriti et al., 2013), which may be due to the worldwide increase in the number of new cases of thyroid cancer reported in a number of publications. However, it is not unknown whether this is a real increase in incidence due to that some areas in Sudan polluted with pesticides exposure (Awadelkarim et al., 2012) or whether it reflects a general insufficiency of technological means and expertise employed to detect small thyroid malignancies, that in the

\section{Acknowledgement}

This work was supported by the Ministry of Higher Education and Scientific Research. Special thanks to Sami at Radiation and Isotopes Centre Khartoum (RICK).

\section{References}

Ahmed, A. A., \& Essa, M. E. A. (2019). Potential of epigenetic events in human thyroid cancer. past may not have discovered(Liu et al., 2017). In the current study, the incidence of thyroid cancer was influenced by several factors, including age, gender, and geographical area. These findings are in line with previous reports that cancer disease is affected by the above mentioned factors (Dorak \& Karpuzoglu, 2012; Finlayson et al., 2014b; Jonklaas et al., 2012).

\section{Conclusion}

Our data reveal an increasing trend in the incidence of thyroid cancer in Sudan. Female are affected more than male and hence, may imply the greater professional, economic, and social impacts. Some ethnic groups were more affected by thyroid cancer. Further studies are required to elucidate the mechanism underlying the vulnerability among those infected age group within a different geographical area.

\section{Ethics approval and consent to participate}

The study was approved by the University of Cape Town, Faculty of Health Sciences Human Research Ethics Committee and by the Western Cape Health Research Committee.

Cancer Genet, 239, 13-21. doi:10.1016/j.cancergen.2019.08.006 
Alexander, E. K., \& Larsen, P. R. (2012). Radioiodine for Thyroid Cancer - Is Less More? New England Journal of Medicine, 366(18), 1732-1733. doi:doi:10.1056/NEJMe1202172

Awadelkarim, K. D., Mariani-Costantini, R., \& Elwali, N. E. (2012). Cancer in the Sudan: An overview of the current status of knowledge on tumor patterns and risk factors. Science of The Total Environment, 423(0), 214-228. doi:http://dx.doi.org/10.1016/j.scitotenv.201 0.09.010

Boltz, M. M., Hollenbeak, C. S., Schaefer, E., Goldenberg, D., \& Saunders, B. D. (2013). Attributable costs of differentiated thyroid cancer in the elderly Medicare population. Surgery, 154(6), 1363-1369; discussion 13691370.. doi:S0039-6060(13)00364-4 [pii] 10.1016/j.surg.2013.06.042

Choi, W. J., \& Kim, J. (2014). Dietary factors and the risk of thyroid cancer: a review. Clin Nutr Res, 3(2), 75-88. doi:10.7762/cnr.2014.3.2.75.

Dal Maso, L., Bosetti, C., La Vecchia, C., \& Franceschi, S. (2009). Risk factors for thyroid cancer: an epidemiological review focused on nutritional factors. Cancer Causes Control, 20(1), 75-86. doi:10.1007/s10552-008-9219-5

Dal Maso, L., Lise, M., Zambon, P., Falcini, F., Crocetti, E., Serraino, D., . . . Franceschi, S. (2011). Incidence of thyroid cancer in Italy, 1991-2005: time trends and age-period-cohort effects. Ann Oncol, 22(4), 957-963.. doi:mdq467 [pii] 10.1093/annonc/mdq467.

Davies, L., \& Welch, H. G. (2006). Increasing incidence of thyroid cancer in the United States, 1973-2002. JAMA, 295(18), 2164-2167. doi:295/18/2164 10.1001/jama.295.18.2164
Dorak, M. T., \& Karpuzoglu, E. (2012). Gender differences in cancer susceptibility: an inadequately addressed issue. Front Genet, 3, 268. doi:10.3389/fgene.2012.00268

Drabe, N., Steinert, H., Moergeli, H., Weidt, S., Strobel, K., \& Jenewein, J. (2016). Perception of treatment burden, psychological distress, and fatigue in thyroid cancer patients and their partners - effects of gender, role, and time since diagnosis. Psychooncology, 25(2), 203209. doi:10.1002/pon.3903

Finlayson, A., Barnes, I., Sayeed, S., Mclver, B., Beral, V., \& Ali, R. (2014a). Incidence of thyroid cancer in England by ethnic group, 2001-2007. $\mathrm{Br} J$ Cancer, 110(5), 1322-1327. doi:10.1038/bjc.2014.4

Finlayson, A., Barnes, I., Sayeed, S., Mclver, B., Beral, V., \& Ali, R. (2014b). Incidence of thyroid cancer in England by ethnic group, 2001-2007. Br J Cancer, 110(5), 1322-1327. Rdoi:bjc20144 [pii]10.1038/bjc.2014.4

Fiore, M., Oliveri Conti, G., Caltabiano, R., Buffone, A., Zuccarello, P., Cormaci, L., . . . Ferrante, M. (2019). Role of Emerging Environmental Risk Factors in Thyroid Cancer: A Brief Review. Int J Environ Res Public Health, 16(7). doi:10.3390/ijerph16071185

Grodski, S., Brown, T., Sidhu, S., Gill, A., Robinson, B., Learoyd, D., . . . Delbridge, L. (2009). Increasing incidence of thyroid cancer is due to increased pathologic detection. Surgery, 144(6), 1038-1043. doi:10.1016/j.surg.2008.08.023

Horn-Ross, P. L., Canchola, A. J., Ma, H., Reynolds, P., \& Bernstein, L. (2011). Hormonal factors and the risk of papillary thyroid cancer in the California Teachers Study cohort. Cancer Epidemiol Biomarkers Prev, 20(8), 1751-1759. doi:1055-9965.EPI-11-0381 [pii] 10.1158/1055-9965.EPI-11-0381

Ilias, I., Alevizaki, M., Lakka-Papadodima, E., \& Koutras, D. A. (2002). Differentiated thyroid 
cancer in Greece: 1963-2000. Relation to demographic and environmental factors. Hormones (Athens), 1(3), 174-178. Retrieved from

http://www.ncbi.nlm.nih.gov/entrez/query.fc gi $? \mathrm{cmd}=$ Retrieve $\& \mathrm{db}=$ PubMed\&dopt=Citation \&list_uids $=17018445$.

Ito, Y., Nikiforov, Y. E., Schlumberger, M., \& Vigneri, R. (2013). Increasing incidence of thyroid cancer: controversies explored. Nat Rev Endocrinol, 9(3), 178-184. doi:nrendo.2012.257 [pii] $10.1038 /$ nrendo.2012.257

Jonklaas, J., Nogueras-Gonzalez, G., Munsell, M., Litofsky, D., Ain, K. B., Bigos, S. T., . . . Sherman, S. I. (2012). The impact of age and gender on papillary thyroid cancer survival. $J$ Clin Endocrinol Metab, 97(6), E878-887. doi:jc.2011-2864 [pii]

10.1210/jc.2011-2864

Kilfoy, B. A., Zheng, T., Holford, T. R., Han, X., Ward, M. H., Sjodin, A., ... Rothman, N. (2009). International patterns and trends in thyroid cancer incidence, 1973-2002. Cancer Causes Control, 20(5), 525-531. doi:10.1007/s10552008-9260-4

Kim, J. R., Kim, B. H., Kim, S. M., Oh, M. Y., Kim, W. J., Jeon, Y. K., ... Kim, I. J. (2014). Low Serum 25 Hydroxyvitamin D Is Associated with Poor Clinicopathologic Characteristics in Female Patients with Papillary Thyroid Cancer. Thyroid.. doi:10.1089/thy.2014.0090

Kuzmickiene, I., \& Stukonis, M. (2010). Cancer incidence among women flax textile manufacturing workers in Lithuania. Occup Environ Med, 67(7), 500-502. doi:67/7/500 [pii]

\subsection{6/oem.2009.048058}

Lin, J. S., Bowles, E. J. A., Williams, S. B., \& Morrison, C. C. (2017). Screening for Thyroid Cancer: Updated Evidence Report and Systematic Review for the US Preventive Services Task Force. JAMA, 317(18), 18881903. doi:10.1001/jama.2017.0562.
Liu, F. C., Lin, H. T., Lin, S. F., Kuo, C. F., Chung, T. T., \& Yu, H. P. (2017). Nationwide cohort study on the epidemiology and survival outcomes of thyroid cancer. Oncotarget, 8(45), 78429-78451. doi:10.18632/oncotarget.19488.

Liu, Y., Su, L., \& Xiao, H. (2017). Review of Factors Related to the Thyroid Cancer Epidemic. Int J Endocrinol, 2017, 5308635. doi:10.1155/2017/5308635.

Mack, W. J., Preston-Martin, S., Bernstein, L., \& Qian, D. (2002). Lifestyle and other risk factors for thyroid cancer in Los Angeles County females. Ann Epidemiol, 12(6), 395-401.. doi:S1047279701002812 [pii]

Miyakawa, M. (2014). Radiation exposure and the risk of pediatric thyroid cancer. Clin Pediatr Endocrinol, 23(3), 73-82. doi:10.1297/cpe.23.73

9991 [pii]

Nettore, I. C., Colao, A., \& Macchia, P. E. (2018). Nutritional and Environmental Factors in Thyroid Carcinogenesis. Int J Environ Res Public Health, 15(8). doi:10.3390/ijerph15081735

Nguyen, Q. T., Lee, E. J., Huang, M. G., Park, Y. I., Khullar, A., \& Plodkowski, R. A. (2015). Diagnosis and treatment of patients with thyroid cancer. Am Health Drug Benefits, 8(1), 30-40. Retrieved from http://www.ncbi.nlm.nih.gov/pubmed/25964 831.

Olson, E., Wintheiser, G., Wolfe, K. M., Droessler, J., \& Silberstein, P. T. (2019). Epidemiology of Thyroid Cancer: A Review of the National Cancer Database, 2000-2013. Cureus, 11(2), e4127. doi:10.7759/cureus.4127.

Pellegriti, G., Frasca, F., Regalbuto, C., Squatrito, S., \& Vigneri, R. (2013). Worldwide increasing incidence of thyroid cancer: update on epidemiology and risk factors. I Cancer Epidemiol, 2013, doi:10.1155/2013/965212. 
Pellegriti, G., Frasca, F., Regalbuto, C., Squatrito, S., \& Vigneri, R. (2013). Worldwide Increasing Incidence of Thyroid Cancer: Update on Epidemiology and Risk Factors. Journal of Cancer Epidemiology, 2013, 10. doi:10.1155/2013/965212

Schlumberger, M., Borget, I., Nascimento, C., Brassard, M., \& Leboulleux, S. (2011). Treatment and follow-up of low-risk patients with thyroid cancer. Nat Rev Endocrinol, 7(10), 625-628. doi:nrendo.2011.133 [pii] 10.1038/nrendo.2011.133.

Schlumberger, M., Catargi, B., Borget, I., Deandreis, D., Zerdoud, S., Bridji, B., . . . Benhamou, E. (2012). Strategies of radioiodine ablation in patients with low-risk thyroid cancer. N Engl J Med, 366(18), 1663-1673. doi:10.1056/NEJMoa1108586.

Siegel, R., Desantis, C., \& Jemal, A. (2014). Colorectal cancer statistics, 2014. CA Cancer J Clin, 64(2), 104-117. doi:10.3322/caac.21220.
Sipos, J. A., \& Mazzaferri, E. L. (2010). Thyroid cancer epidemiology and prognostic variables. Clin Oncol ( $R$ Coll Radiol), 22(6), 395-404. doi:S0936-6555(10)00174-3 [pii] 10.1016/j.clon.2010.05.004.

Yabroff, K. R., Gansler, T., Wender, R. C., Cullen, K. J., \& Brawley, O. W. (2019). Minimizing the burden of cancer in the United States: Goals for a high-performing health care system. $C A: A$ Cancer Journal for Clinicians, 69(3), 166-183. https://doi.org/10.3322/caac.21556. doi:10.3322/caac.21556.

Yao, R., Chiu, C. G., Strugnell, S. S., Gill, S., \& Wiseman, S. M. (2011). Gender differences in thyroid cancer: a critical review. Expert Review of Endocrinology \& Metabolism, 6(2), 215-243. doi:doi:10.1586/eem.11.9.

Zevallos, J. P., Xu, L., \& Yiu, Y. (2014). The impact of socioeconomic status on the use of adjuvant radioactive iodine for papillary thyroid cancer. Thyroid, 24(4), 758-763. doi:10.1089/thy.2013.0409. 